\title{
Extracellular Matrix Proteins in Hemostasis and Thrombosis
}

\author{
Wolfgang Bergmeier ${ }^{1}$ and Richard O. Hynes ${ }^{2}$ \\ ${ }^{1}$ Department of Biochemistry and Biophysics, University of North Carolina, Chapel Hill, \\ North Carolina 27599-7035 \\ ${ }^{2}$ Howard Hughes Medical Institute, Koch Institute for Integrative Cancer Research, Massachusetts \\ Institute of Technology, Cambridge, Massachusetts 02139 \\ Correspondence: rohynes@mit.edu
}

\begin{abstract}
The adhesion and aggregation of platelets during hemostasis and thrombosis represents one of the best-understood examples of cell-matrix adhesion. Platelets are exposed to a wide variety of extracellular matrix (ECM) proteins once blood vessels are damaged and basement membranes and interstitial ECM are exposed. Platelet adhesion to these ECM proteins involves ECM receptors familiar in other contexts, such as integrins. The major plateletspecific integrin, $\alpha \mathrm{llb} \beta 3$, is the best-understood ECM receptor and exhibits the most tightly regulated switch between inactive and active states. Once activated, $\alpha$ llb $\beta 3$ binds many different ECM proteins, including fibrinogen, its major ligand. In addition to $\alpha$ llb $\beta 3$, there are other integrins expressed at lower levels on platelets and responsible for adhesion to additional ECM proteins. There are also some important nonintegrin ECM receptors, GPIb$\mathrm{V}-\mathrm{IX}$ and GPVI, which are specific to platelets. These receptors play major roles in platelet adhesion and in the activation of the integrins and of other platelet responses, such as cytoskeletal organization and exocytosis of additional ECM ligands and autoactivators of the platelets.
\end{abstract}

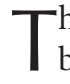
he balance between hemostasis and thrombosis relies on a finely tuned adhesive response of blood platelets. Inadequate adhesion leads to bleeding, whereas excessive or inappropriate adhesion leads to thrombosis. Resting platelets are nonadhesive anuclear discs and do not interact with the vessel wall, but they have a plethora of receptors that sense activating signals (agonists) of various sorts. The activating signals include soluble factors such as thrombin, adenosine diphosphate (ADP), and epinephrine, all of which act on
G-protein-coupled receptors (GPCRs) on the platelets. In addition, certain receptors for extracellular matrix (ECM) proteins (e.g., GPIb, GPVI, and some integrins) can also act as activating receptors. These diverse receptors trigger intracellular signaling pathways that activate (1) actin assembly leading to cell shape change and extension of filopodia; (2) exocytosis of secretory granules that release additional platelet agonists as well as adhesive ECM proteins; and (3) activation of additional cell-surface receptors such as the major

Editors: Richard O. Hynes and Kenneth M. Yamada

Additional Perspectives on Extracellular Matrix Biology available at www.cshperspectives.org

Copyright (C) 2012 Cold Spring Harbor Laboratory Press; all rights reserved; doi: 10.1101/cshperspect.a005132

Cite this article as Cold Spring Harb Perspect Biol 2012;4:a005132 
platelet-specific integrin, $\alpha \operatorname{IIb} \beta 3$, that contribute further to the adhesion and aggregation of activated platelets. Thus, the interactions of platelet-ECM adhesion receptors with ECM proteins from the vessel wall, from the plasma, and from the platelets themselves, are central to both the initial adhesion and the subsequent activation and aggregation of platelets (VargaSzabo et al. 2008). These adhesive interactions, together with coagulation (to which platelets also contribute), generate the fibrin clot, essentially a facultative ECM that forms the initial occlusion of the damaged vessel but also serves as a subsequent ECM substrate for wound healing. In this article, we will review what is known about the roles of ECM proteins and their receptors in platelet adhesion and aggregation, summarize the roles of the clot and provisional ECM in subsequent wound healing, point out various unanswered questions, and discuss briefly the contributions of the relevant cellECM interactions to disease and the potential for therapeutic interventions.

\section{THE ENDOTHELIUM, THE BASEMENT MEMBRANE, AND THE ECM OF THE VESSEL WALL}

Blood vessels are lined by a monolayer of endothelial cells, which form adhesion complexes, including tight junctions, sealing the lumen of the vessels from the underlying basement membrane and interstitial matrix. The apical surfaces of quiescent endothelial cells in undamaged and noninflamed vessels are nonadhesive to circulating cells, including platelets. This is both because of the nature of their plasma membrane and cell-surface proteins, including an extensive glycocalyx, and to the fact that the apical surfaces lack any ECM. Endothelial cells actively synthesize ECM proteins but they deposit them basally or retain them in secretory granules, known as Weibel-Palade bodies. Beneath the endothelial cell layer is a basement membrane, which like other basement membranes contains type IV collagen, laminins, nidogens, and perlecan (Yurchenco 2011). The predominant isoforms in vascular basement membranes are nidogen 2 and laminins 8 and 10 (laminins
411 and 511), although there is some variation among vascular beds (Hallmann et al. 2005). Whether or not the collagen IV isoforms vary has not been investigated. Unlike other basement membranes, the endothelial basement membrane also contains von Willebrand factor, a large ECM protein produced only by endothelial cells and the megakaryocyte/platelet lineage. Von Willebrand factor (VWF) plays a crucial role in hemostasis and thrombosis (see below). In angiogenic vessels, fibronectin is also a prominent constituent of the endothelial basement membrane, although it is found at lower levels in quiescent vessels. In addition to the change in level, the splice isoforms of fibronectin differ between angiogenic and quiescent vessels - the former contain the alternatively spliced EIIIA and EIIIB domains (Schwarzbauer and DeSimone 2011), whereas the latter do not. Both the levels of fibronectin and the inclusion of these two splice segments are also elevated in vessels during atherosclerosis and after myocardial infarction or wound healing, and probably in other situations in which the endothelial cells are activated (Astrof and Hynes 2009). In addition, certain other ECM proteins are found in certain vascular beds (Hallmann et al. 2005). Thus, the ECM proteins in the basement membranes of different vessels can vary.

Beneath the intimal endothelial layer lie smooth muscle cells (in large vessels) or pericytes (in small vessels). Pericytes and endothelial cells are invested within a common basement membrane, whereas smooth muscle cells in larger vessels form a separate, so-called medial layer with its own extracellular matrix components including elastin, collagens, and fibrillin microfibrils (Wagenseil and Mecham 2009). Arteries have more smooth muscle cell layers and more elastin than do veins. Outside the smooth muscle cell layer of large vessels, there is an adventitial layer containing fibroblasts, fibrillar collagens, fibronectin, and many other ECM proteins. The environment beyond the adventitium of large vessels or the pericyte layer of small vessels varies with the tissue. In brain vessels there is a closely apposed layer of astrocyte end-feet surrounding the vascular unit, which contributes to the 
blood-brain barrier and has a separate and distinct basement membrane of its own (Sixt et al. 2001). Many other small vessels (arterioles, venules, and capillaries) are surrounded by an interstitial matrix, again containing fibrillar collagens, fibronectin, and other ECM proteins. In the interstitium, fibrillar collagen types I, III, and $\mathrm{V}$ are the most prominent (Voss and Rauterberg 1986). Therefore, the ECM proteins to which platelets and leukocytes become exposed depend both on the degree of injury to the vessels and on the type of vessel involved (Fig. 1). Mild injuries such as damage to the endothelial layer will expose type IV collagen, laminins, and VWF, and in some situations, fibronectins, whereas more extensive injuries exposing the smooth muscle layer or interstitial ECM will expose them in addition to fibrillar collagens, elastin, microfibrils, and other ECM proteins.

\section{PLATELET-ECM INTERACTIONS: INITIAL PLATELET ADHESION}

In this section, we will summarize our understanding of the molecular mechanisms by which platelets sense exposed solid-phase ECM and

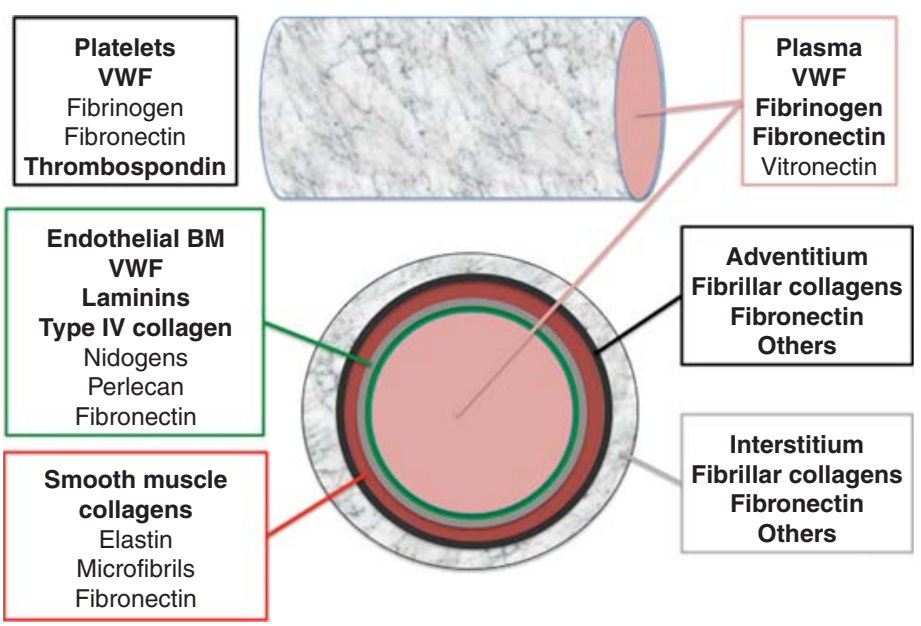

Figure 1. ECM protein sources for hemostasis. Platelets have access to a wide variety of ECM proteins with which to interact. Multiple ECM proteins circulate in plasma, the most important for hemostasis being VWF and fibrinogen. Platelets themselves have multiple ECM proteins stored in secretory $\alpha$ granules, which release their contents on platelet activation; some of these secreted platelet-ECM proteins are released as soluble proteins, others are retained at the surfaces of the activated platelets, often by interactions with platelet adhesion receptors. The lumenal surfaces of endothelial cells (green) are free of ECM, but the basement membrane beneath them (gray) contains the usual basement membrane proteins plus VWF. Basement membranes of some vessels also contain additional ECM proteins. The layers below the basement membrane vary with vessel type; shown here are a smooth muscle layer (red) containing elastin, microfibrils, collagens, and fibronectin, and the surrounding connective tissue adventitial layer (black), which contains fibrillar collagens, fibronectin, and other ECM proteins. The interstitium around blood vessels (gray mesh) obviously varies with the tissue but typically contains fibrillar collagens, fibronectin, and diverse other ECM proteins. Therefore, the ECM proteins available to mediate platelet adhesion vary greatly depending on the vessels involved and on the severity of the injury (e.g., whether or not ECM below the basement membrane is exposed). The ECM also evolves considerably during the course of a hemostatic or thrombotic event. Circulating VWF can be bound directly by platelets or can bind to exposed collagen fibers. Platelet activation, either by soluble factors such as thrombin, ADP, and epinephrine or by ECM proteins such as VWF, collagens, and laminins, releases additional ECM proteins and activates receptors that can recruit additional ECM proteins such as fibrinogen. Platelets have receptors for many, maybe all, of these ECM proteins and a reasonable hypothesis is that they have evolved to adhere to whatever ECM proteins they encounter, no matter where the lesion occurs or how severe the injury. ECM proteins known to have major roles in platelet adhesion and aggregation are bolded. 
their responses to these interactions. Platelet adhesion under arterial high shear conditions (as in arteries) is a multistep process that requires interaction of various receptors, some generic and some platelet-specific, with their ligands in the ECM (Varga-Szabo et al. 2008). A critical step in the adhesion response is the tethering of platelets to VWF present in the ECM. This initial adhesion step is mediated with a high on-rate by the constitutively active platelet-specific receptor for VWF, GPIb-V-IX. This interaction is reversible and leads to rolling or sliding of the platelets along the exposed VWF-rich ECM, which can be the exposed endothelial basement membrane or fibrillar collagen to which circulating VWF has bound (see below). Subsequent to GPIb-VWF-mediated tethering, other platelet receptors with lower on-rates but higher affinities can engage their ligands expressed in the ECM. Arguably the most important interactions at these early stages are those of collagen with GPVI, a member of the immunoglobulin superfamily, and with integrin $\alpha 2 \beta 1$. Another significant interaction is provided by laminin binding to GPVI and integrin $\alpha 6 \beta 1$. Especially when activated by collagen, GPVI provides stimulatory signals, which trigger various platelet responses such as activation of $\alpha \operatorname{IIb} \beta 3$ integrin, granule release, the generation of lipid mediators, cytoskeletal rearrangements, and surface exposure of procoagulant phosphatidylserine. Engagement of platelet $\alpha \operatorname{IIb} \beta 3$ integrin is crucial for firm platelet adhesion to the substrate, for platelet aggregation, and also for strengthening of the stimulatory signal owing to integrin outside-in signaling (see below).

\section{VWF}

VWF is a glycoprotein constituent of the vascular basement membrane and also circulates in plasma as large multimers ranging from 500 to $10,000 \mathrm{kDa}$. The mature VWF monomer consists of 2050 residues and contains a number of domains important for the function of the molecule, as well as cysteine residues for crosslinking into dimers and multimers via disulfide bonds (Fig. 2) (Wagner 1990; Ruggeri 1997; Sadler 2009). Endothelial cells (ECs) and megakaryocytes are the only cells that synthesize VWF. In ECs, VWF is either constitutively secreted or targeted to storage granules, the Weibel-Palade bodies, for agonist-induced secretion. In contrast, only agonist-induced secretion from $\alpha$ granules is observed in platelets. Consequently, plasma VWF is essentially completely derived from ECs. VWF multimers released from storage granules are extremely large and designated as ULVWF (ultralarge von Willebrand factor). ULVWF is biologically hyperactive, as it forms stronger bonds with its platelet receptor, GPIb $\alpha$ (Arya et al. 2002), presumably as a consequence of multipoint binding, and it binds better to ECM than do the typical smaller plasma multimers. Upon secretion, ULVWF multimers are cleaved to less active smaller-sized multimers by the protease ADAMTS13 (a disintegrinlike and metalloprotease with thrombospondin type I repeats-13) under conditions of fluid shear stress (see below). Deficiency of ADAMTS13 function-either familial (mutation in the ADAMTS13 gene) or acquired (inhibitory antibodies generated against ADAMTS13)—has been linked to the pathogenesis of thrombotic thrombocytopenic purpura (TTP), a disorder of thrombotic microangiopathy (Levy et al. 2001; Lammle et al. 2005; Sadler 2008). Studies in mice lacking ADAMTS-13 (Motto et al. 2005; Banno et al. 2006) confirmed previous findings in patients (Furlan and Lammle 2001; Veyradier et al. 2004), which suggested that genetic and environmental factors, in addition to ADAMTS13 deficiency, are required to trigger TTP. In circulation, VWF binds noncovalently to coagulation factor VIII (FVIII), thus protecting it from proteolysis. Consequently, humans and mice lacking VWF are characterized by a marked decrease in plasma FVIII levels and a significant increase in the "activated partial thromboplastin time (aPTT)," a measure of contact-phase-dependent coagulation (Weiss et al. 1977; Denis et al. 1998). Thus, VWF facilitates primary adhesion (tethering) of platelets to the exposed ECM and it efficiently localizes FVIII to sites of vascular injury.

As mentioned, VWF is a constituent of endothelial basement membranes and is also 


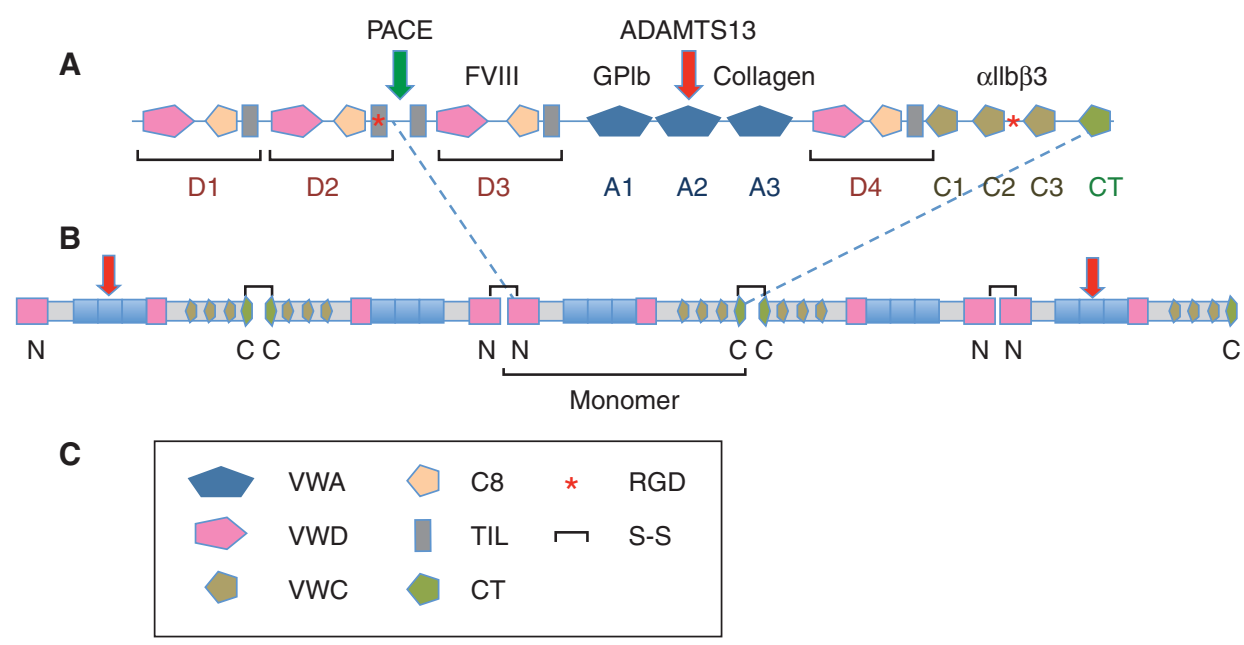

Figure 2. von Willebrand factor. (A) Domain structure and binding sites of von Willebrand factor (VWF). The standard domains (as per the SMART protein domain site http://smart.embl-heidelberg.de) are shown in the diagram. In the hemostasis field, VWF is traditionally designated with $\mathrm{A}, \mathrm{B}, \mathrm{C}$, and D repeats. The $\mathrm{A}$ repeats correspond with VWA domains and each D repeat corresponds with a combination of tandem VWD/C8/TIL domains. The carboxyl terminus of the molecule comprises three VWC domains and a carboxyterminal knot domain. These do not correspond exactly with the B and C repeats. The C8, TIL, VWC, and CT domains are all cysteine-rich, making the drawing of boundaries between domains nontrivial; here we have used the standard domains based on hidden Markov models and comparisons with other proteins. Binding sites are shown for the coagulation cofactor, factor VIII (D3 repeat), for collagen (collagen binds the A3 domain) and for the two major receptors for VWF, the GPIb-V-IX complex (A1 domain) and integrin $\alpha I I b \beta 3$ (an RGD site between the last two VWC domains; see text). During biosynthesis and processing, the prodomain comprising D1 and D2 repeats is separated from the mature VWF by cleavage after a dibasic amino acid pair by the enzyme PACE ( paired basic amino acid cleaving enzyme). VWF monomers then associate into dimers $(\sim 500 \mathrm{kDa})$ through disulfide bonding of their carboxy-terminal domains. (B) VWF multimerization. The tail-tail VWF dimers then associate by amino-terminal disulfide bonding into ultralarge VWF polymers $(>10$ million Da; $>40$ monomers) that are stored in Weibel-Palade bodies. When these are released, they form enormous extended fibrils, which extend under the shear forces in the circulation and are cleaved by ADAMTS13 to smaller but still large multimers containing fewer than 40 monomers. ADAMTS13 cleaves in the A2 VWA domain (see text). (C) Domain key shows the domains making up VWF and other features such as intersubunit $\mathrm{S}-\mathrm{S}$ bonds and the integrin-binding RGD site.

released by activated ECs or platelets. Its major role in hemostasis and thrombosis occurs under conditions of high shear, and the very large size of VWF multimers plays an important role in the sensitivity of VWF to shear. Several of the interactions of VWF are subject to modulation by conformational changes in the three VWA domains (A1,A2,A3) of VWF (see Fig. 2), including mechanical deformation by shear stress. The ultralarge multimers found in TTP become extended under flow and bind platelets through the constitutively active GPIbV-IX complex. Cleavage of the A2 domain by
ADAMTS13 requires shear to expose the cleavage site (Zhang et al. 2009; Zhou et al. 2010). The smaller (but still large) multimers arising after cleavage by ADAMTS13 bind through the A3 domain to fibrillar collagens exposed by injury, and this interaction plus shear forces expose the Al domain for interaction with GPIb $\alpha$. Shear also enhances the interactions of the A3 domain with collagen (Schneider et al. 2007) in part by exposing the A3 domain. Furthermore, the VWF-A1/GPIb $\alpha$ interaction is a flex bond whose affinity increases under shear stress (Kim et al. 2010). 
W. Bergmeier and R.O. Hynes

\section{The GPIb-V-IX Receptor Complex}

The GPIb-V-IX receptor complex consists of four gene products: GPIb $\alpha$, GPIb $\beta$, GPIX, and GPV in 2:4:2:1 ratios (Fig. 3) (Andrews et al. 2003; Luo et al. 2007; Bergmeier et al. 2008;
Clemetson and Clemetson 2008). The aminoterminal region of GPIb $\alpha$, comprising eight LRR repeats plus amino- and carboxy-terminal caps, is the major ligand-binding domain for VWF, but it also binds various other ligands such as thrombin, high molecular weight
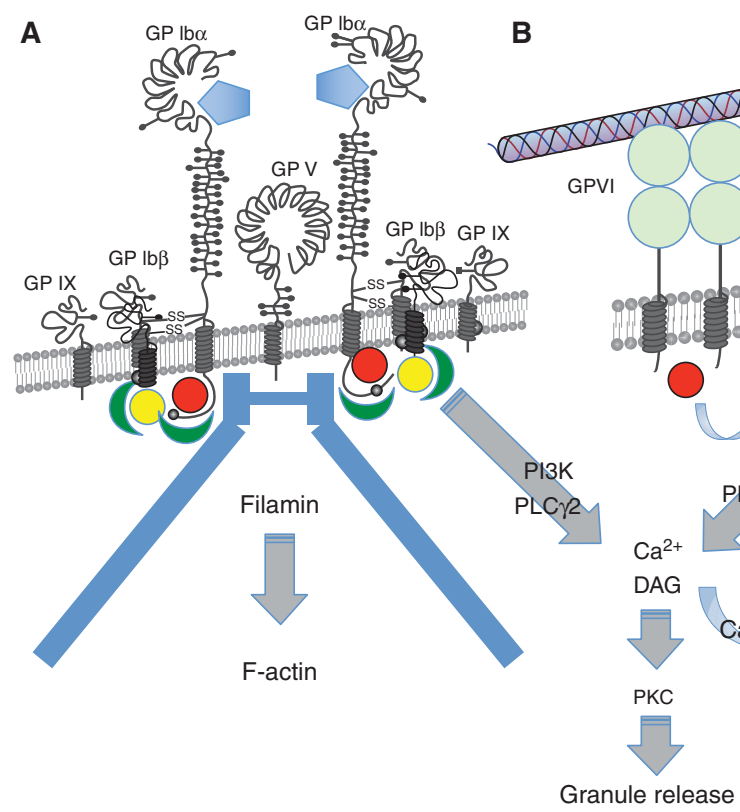

Figure 3. Platelet receptors for ECM proteins. (A) The GPIb-V-IX complex-the major receptor for von Willebrand factor (VWF), which binds through its Al VWA domain (blue pentagon) to the LRR repeat region of GPIb $\alpha$. The receptor is constitutively active and has nine subunits: two copies of GPIb $\alpha$, each of which associates with two copies of GPIb $\beta$ and one of GPIX - the two GPIb-IX heterotetramers are associated with a single copy of GPV. The cytoplasmic domains of GPIb $\alpha$ and GPIb $\beta$ bind filamin and a number of signal transduction proteins, including Src (red sphere), 14-3-3 (green), and calmodulin (yellow), and activate PI3-kinase and phospholipase Cy2. (B) GPVI, a receptor for fibrillar collagens, has two Ig domains and is noncovalently associated with the $F c$ receptor- $\gamma(\mathrm{FcR} \gamma)$ chain, which acts as a signal transduction subunit. On ligand binding, a Src family kinase (red sphere) phosphorylates two tyrosine residues in the immunoreceptor tyrosine-based activation motif (ITAM) motif within the FcR $\gamma$ chain. Syk kinase (orange) binds the phosphorylated ITAM motif and activates phospholipase $\mathrm{C} \gamma 2 . \mathrm{Ca}^{2+}$ generated downstream from IP3 released by PLC stimulates the Rap-GEF, CalDAG-GEF1, to activate Rap1, which leads to association of talin-1 with integrins, thereby activating them. Diacylglycerol (DAG) also induces PKC-mediated release of granule contents, including soluble agonists and ECM components. $(C)$ Integrins are activated by the VWF and collagen receptors (or by GPCRs bound by other platelet agonists) through binding of talin-1 and kindlin-3 to their $\beta$ subunit cytoplasmic domains. Once activated, integrins can bind their ECM protein ligands. Several $\beta 1$ integrins are expressed on platelets at a few thousand copies per platelet, most notably $\alpha 2 \beta 1$ and $\alpha 6 \beta 1$, receptors for collagens and laminins, respectively, but also $\alpha 5 \beta 1$, a receptor for fibronectin and fibrillin and $\alpha \mathrm{v} \beta 3$, which binds many ECM proteins (see text). The major platelet integrin, $\alpha \operatorname{IIb} \beta 3$, is present at $60-80,000$ copies per platelet and is the major receptor mediating platelet aggregation through its binding to fibrinogen (and also to fibronectin, VWF, and several other ECM proteins - see text). Most integrins bind their ligands (black) through a binding site at the junction between the head domains of the two subunits-a $\beta$ propellor domain in the $\alpha$ subunit (dark blue) and a VWA domain in the $\beta$ subunit (red). In contrast, $\alpha 2 \beta 1$ binds through an additional VWA domain inserted into the $\beta$ propellor domain (not shown). 
kininogen, coagulation factors XI and XII, thrombospondin-1, the integrin Mac-1/ $\alpha \mathrm{M} \beta 2$, and P-selectin. GPIb $\alpha$ is a single-pass transmembrane receptor expressed in high copy numbers on the platelet surface and is thought to be constitutively active. Its binding to the A1 domain of VWF requires arterial shear rates and is enhanced by increasing shear stress. As outlined above, this shear dependency is attributed to a conformational change within VWF that is required to expose the A1 domain. Recently solved crystal structures for the unliganded and liganded amino-terminal domain of GPIb $\alpha$ identified an 11-residue sequence (AA 229-240) within this domain that undergoes a major conformational change from an unstructured loop to a $\beta$-hairpin ( $\beta$-switch region) (Huizinga et al. 2002; Dumas et al. 2004). Interestingly, naturally occurring gainof-function (GOF) and loss-of-function (LOF) mutations also target this region (Russell and Roth 1993; Moriki et al. 1997; Doggett et al. 2003), suggesting a potential mechanism for affinity regulation of this receptor. Flow simulations confirmed this hypothesis, as they predict instability in the $\beta$-switch region in unliganded GPIb $\alpha$, which transitions to a $\beta$-hairpin under conditions of flow (Chen et al. 2008; Lou and Zhu 2008). GOF or LOF mutations make this shear-induced switch easier or harder, respectively. Thus, shear stress leads to conformational changes in both VWF and GPIb $\alpha$.

The importance of both the GPIb-V-IX receptor and VWF for hemostasis is shown by the strong bleeding diathesis found in BernardSoulier syndrome (BSS) patients, who lack the GPIb-V-IX complex on the platelet surface, or in patients lacking VWF (Bernard and Soulier 1948; Caen et al. 1976; Nurden 1999). Similar bleeding phenotypes are found for mice deficient in GPIbo (Ware et al. 2000) or VWF (Denis et al. 1998). Interestingly, studies using transgenic mice indicate that the role of GPIb $\alpha$ exceeds that of VWF in the development of arterial thrombosis, suggesting that one or more of the other ligands contributes to GPIb $\alpha$ function during thrombus formation (Bergmeier et al. 2006). Thrombus formation in venules, however, is more dependent on VWF than on
GPIb, which likely reflects the importance of VWF as a stabilizer of plasma FVIII (Chauhan et al. 2007). Engagement of GPIb-V-IX leads to various intracellular changes such as calcium mobilization, the rearrangement of the cytoskeleton, granule release, and activation of the $\alpha I I b \beta 3$ integrin (Fig. 3). Numerous cytoplasmic binding partners have been described for GPIb $\alpha$ (14-3-3 $\zeta$, filamin, Src family kinases, phosphatidylinositol-3 kinase, and phospholipase C) and GPIb $\beta$ (calmodulin and 14-3-3 $\zeta$ ). Some of these signal transduction pathways contribute to the activation of platelet functions, but the exact nature of all the signaling responses is still unclear (see Fig. 3) (Andrews et al. 2007; Du 2007).

\section{Integrin $\alpha$ ll b $\beta 3$}

The second major platelet receptor for VWF is the platelet-specific integrin, $\alpha \operatorname{IIb} \beta 3$, previously known as glycoprotein GPIIb/IIIa. This is probably the best-studied integrin and exemplifies the most exquisite on-off regulation, consistent with the requirement for tightly regulated adhesion in hemostasis (Shattil and Newman 2004; Bennett et al. 2009). Binding of the RGD site in the carboxy-terminal region of VWF by $\alpha \operatorname{IIb} \beta 3$ requires activation of this integrin, which, unlike GPIb-V-IX, is not constitutively active on resting platelets. Therefore, engagement of $\alpha \operatorname{IIb} \beta 3$ occurs predominantly later in the adhesive cascade, during aggregation, in which it plays an essential role. $\alpha \operatorname{IIb} \beta 3$ is active under both low and high shear conditions, unlike GPIb-V-IX, and the relative importance of these two receptors for VWF therefore differs depending on the shear stress. The crucial importance of $\alpha \mathrm{IIb} \beta 3$ is clear from the genetic disease, Glanzmann thrombasthenia, in which platelets lack this integrin (Nurden 2006) and from genetically engineered mice lacking $\alpha \operatorname{IIb} \beta 3$ (Hodivala-Dilke et al. 1999)_both have major bleeding problems and their platelets fail to aggregate. The molecular details of the interactions of $\alpha \mathrm{IIb} \beta 3$ with VWF and other ECM ligands during platelet aggregation will be covered in more detail later in this article. 
W. Bergmeier and R.O. Hynes

\section{Collagens}

Collagens are described in detail by RicardBlum (Ricard-Blum 2011). Fibrillar collagens are potent activators of GPVI (see below) and are thus considered strong triggers for thrombosis. Interestingly, however, fibrillar collagens type I, III, and V are found in the deeper layers of the ECM and are thus not accessible after superficial injury. Collagens type IV, VIII, and XVIII are expressed in the basement membrane, i.e., closer to the endothelial layer. Type IV collagen forms two-dimensional networks in the basement membrane rather than fibrils (Ricard-Blum 2011; Yurchenco 2011), and based on in vitro studies (Jung et al. 2008), is thought to be considerably less potent than fibrillar collagens with regard to engaging GPVI or binding VWF. Studies in vivo, however, suggest that type IV collagen triggers GPVIdependent thrombosis induced by superficial injury to the vessel wall (Hechler et al. 2010), confirming earlier studies that indicated a supportive role for collagen type IV in platelet adhesion and thrombosis at low and high shear rates (Henrita van Zanten et al. 1996; Jarvis et al. 2002).

As outlined above, VWF binding to collagen is an early step in the adhesion cascade following vascular damage. The $\mathrm{A} 3$ domain has been identified as the most critical domain within VWF for this interaction to occur, and inhibitors of this domain have proven beneficial in reducing thrombosis in animals (Deckmyn et al. 2005). Platelets then roll along the deposited VWF, allowing collagen-specific platelet receptors to engage.

\section{GPVI Receptor}

GPVI is a $60-65 \mathrm{kDa}$ type I transmembrane glycoprotein belonging to the immunoglobulin superfamily of adhesion receptors (Clemetson and Clemetson 2001; Nieswandt and Watson 2003; Jung and Moroi 2008). It contains two immunoglobulinlike domains (D1 and D2), which are connected with the transmembrane and cytoplasmic domain via a mucinlike stalk (see Fig. 3). GPVI is noncovalently associated with the $F c$ receptor $(F c R) \gamma$ chain, which serves as the signal-transducing subunit of the receptor in human as well as mouse platelets. GPVIdeficient patients suffer from a mild bleeding diathesis, and their platelets respond poorly to collagen or collagen mimetics (Moroi et al. 1989; Arai et al. 1995; Dumont et al. 2009; Hermans et al. 2009). Platelets from GPVI-deficient mice (Kato et al. 2003) also fail to respond to collagen, although they show a normal response to stimulation via GPCRs. The GPVI crystal structure suggests that the ligand-binding site resides within the D1 domain and that the D2 domain facilitates the dimerization of the receptor required to support ligand binding (Horii et al. 2006). Engagement of GPVI further requires repetitive Gly-Pro-Hyp sequences within the collagen fiber, which facilitate the clustering of the receptor on the cell surface (Knight et al. 1999). Signaling downstream from GPVI occurs via a similar pathway to that used by immunoreceptors (Nieswandt and Watson 2003), initiated by the tyrosine phosphorylation of the FcR $\gamma$-chain immunoreceptor tyrosine-based activation motif (ITAM) by a Src-like kinase (Fyn or Lyn). The signaling events directly downstream from binding of Syk to the tyrosine-phosphorylated ITAM of the FcR $\gamma$-chain orchestrate the activation of phospholipase $\mathrm{C} \gamma 2$, leading to the generation of the second messengers, diacylglycerol (DAG) and calcium (see Fig. 3). The guanine nucleotide exchange factor, CalDAG-GEFI (RasGRP2), senses increased intracellular calcium concentrations and regulates various platelet responses via activation of the small GTPase Rap1 (Crittenden et al. 2004; Stefanini et al. 2009). DAG itself induces the activation of protein kinase C, a key regulator of platelet granule release and thus critical for positive feedback activation of the cell (Harper and Poole 2010). Downstream from Rap1, talin-1 (Nieswandt et al. 2007; Petrich et al. 2007) and kindlin-3 (Moser et al. 2008) bind to the cytoplasmic tail of integrins, thereby facilitating inside-out activation of these adhesion receptors and firm platelet adhesion to the collagen/VWF matrix (Campbell and Humphries, 2011; Wickstrom et al, 2011). GPVI signaling is also critical for the platelet 
procoagulant response, i.e., the ability of activated platelets to promote clotting (Heemskerk et al. 1999; Dale 2005). Signaling via GPVI, unlike that initiated by engagement of GPCRs, leads to a sustained increase in intracellular calcium levels required for the disruption of the asymmetry of the lipid bilayer. The resulting surface exposure of negatively charged phosphatidylserine provides a catalytic surface for the assembly of plasma clotting factors and thus catalyzes the generation of the fibrin clot (see below).

Integrin $\alpha 2 \beta 1$

Firm attachment of platelets to collagen is mediated by integrin $\alpha 2 \beta 1$ and indirectly by integrin $\alpha \operatorname{IIb} \beta 3$ binding to collagen-bound VWF (see above). Compared to $\alpha \operatorname{IIb} \beta 3, \alpha 2 \beta 1$ integrin is expressed on platelets at low copy numbers ( 2000-4000 copies per platelet); however, its surface expression level can vary up to 10-fold between individuals owing to the C807T genetic polymorphism of $\alpha 2$ (Kunicki et al. 1997). Like other integrins, $\alpha 2 \beta 1$ is expressed on resting platelets in a low-affinity state (Nuyttens et al. 2011). Upon cellular activation, the extracellular domains of both subunits extend upwards and the integrin shifts to a high-affinity state. Critical for collagen binding to $\alpha 2 \beta 1$ is an I domain inserted into the $\beta$-propeller domain of the $\alpha 2$ subunit. The I domain is a VWA domain homologous with the collagen-binding A3 domain in VWF. Both these domains contain a conserved metal-ion-dependent adhesion site (MIDAS) involved in the binding of collagen. Within the collagen molecule, GFOGER sequences (in which $\mathrm{O}$ stands for hydroxyproline) were identified as the high-affinity binding site for $\alpha 2 \beta 1$ - the glutamate residue (E) coordinates the metal ion in the MIDAS site (Emsley et al. 2000).

Early studies with platelets from patients with a deficiency in $\alpha 2 \beta 1$ suggested that this integrin plays a central role in sensing exposed collagen fibrils (Nieuwenhuis et al. 1985; Kehrel et al. 1988). However, the relationship between the clinical symptoms and the proposed $\alpha 2 \beta 1$ deficiency was later questioned (Nieswandt and Watson 2003), as studies in genetically modified mice showed a key role for GPVI but not for $\alpha 2 \beta 1$ in collagen-induced platelet activation (Nieswandt et al. 2001). These results were partially confirmed under physiological flow conditions ex vivo and in vivo, in which deficiency in $\alpha 2 \beta 1$ provided only limited or no protection from thrombosis (Nuyttens et al. 2011). Based on these studies, a model in which $\alpha 2 \beta 1$ contributes to the stability of collagen-induced thrombi by (1) anchoring the first layer of platelets to the collagen surface and (2) contributing to GPVI-mediated platelet activation, has emerged. Consequently, impaired $\alpha 2 \beta 1$ expression/function results in thrombus instability, most likely because of the important role of $\alpha 2 \beta 1$ outside-in signaling in the generation of the second-wave mediator thromboxane A2 (Kuijpers et al. 2007; Stefanini et al. 2009).

\section{Laminins and Laminin Receptors}

Laminins are heterotrimeric glycoproteins consisting of $\alpha, \beta$, and $\gamma$ chains (Yurchenco 2011). Basement membranes of all blood vessels predominantly express $\alpha 4$ or $\alpha 5$ laminin subtypes (Hallmann et al. 2005). Platelets express at least three receptors, which directly interact with laminin: integrin $\alpha 6 \beta 1$ (Ill et al. 1984; Sonnenberg et al. 1988), GPVI (Inoue et al. 2006; Ozaki et al. 2009), and an uncharacterized $67 \mathrm{kDa}$ protein (Tandon et al. 1991; Nelson et al. 2008). So far, only the roles of $\alpha 6 \beta 1$ integrin and GPVI in platelet adhesion to laminin are well documented. Interestingly, the processes mediating platelet adhesion to laminin are similar to those regulating platelet-collagen interactions. Under arterial flow conditions, platelet adhesion to laminin requires an initial adhesion step mediated by the GPIb $\alpha$-VWF interaction. However, binding of $\alpha 6 \beta 1$ to laminin is a prerequisite for binding of GPVI, whereas binding of $\alpha 2 \beta 1$ to collagen predominantly occurs as a response to engagement of GPVI by collagen. This difference may be explained by the 10-fold lower affinity of GPVI for laminin when compared with collagen (Inoue et al. 2006). The inability 
of laminin to induce platelet aggregation in suspension is likely also the result of this lower affinity. In the absence of GPVI, platelets adhere normally to laminin but fail to spread properly.

So far, it is not clear if the platelet-laminin interaction provides a critical contribution to thrombosis and hemostasis. Compared to collagen, laminin seems to be a weak platelet agonist. Thus, exposure of collagen in the deeper layers of the extracellular matrix will likely mask any role of laminin in the basement membrane. Superficial injuries, however, will not expose fibrillar collagens, and under these conditions, laminin-mediated adhesion may be more important.

As noted earlier, platelets can be exposed to a wide variety of ECM protein ligands, depending on the situation (see Fig. 1). While VWF and collagen are the main agonistic ligands, binding as they do to constitutively active receptors (GPIb-V-IX and GPVI, respectively) and subsequently to activated integrins $(\alpha \operatorname{IIb} \beta 3$ and $\alpha 2 \beta 1$, respectively), platelets also express other ECM receptor integrins at levels comparable to their levels of $\alpha 2 \beta 1$ (Varga-Szabo et al. 2008). These other integrins are $\alpha 5 \beta 1$, a receptor for fibronectin and fibrillin, and $\alpha \mathrm{v} \beta 3$, a promiscuous receptor that can bind almost any ECM protein containing an exposed RGD motif (e.g., thrombospondin, vitronectin, nidogens, fibronectin, and fibrillin, as well as the major platelet ligands, VWF and fibrinogen). It is currently unclear what role these integrins, which presumably require activation, may play in platelet adhesion, and this is an area for future study.

\section{PLATELET-PLATELET INTERACTIONS: PLATELET AGGREGATION}

For the hemostatic plug to form, additional circulating platelets need to be incorporated into the growing thrombus. Initially, recruitment of additional platelets depends on mechanisms similar to those that regulate platelet adhesion to the ECM. Transient adhesion under elevated shear stress (arterial shear rates) requires the interaction of GPIb $\alpha$ with one of its ligands, most prominently VWF (Kulkarni et al. 2000;
Bergmeier et al. 2006). At low shear conditions (venous shear rates), however, platelet adhesion does not depend on GPIb $\alpha$, and platelet aggregation is largely dependent on the major platelet integrin, $\alpha \operatorname{IIb} \beta 3$ (Savage et al. 1996; Chauhan et al. 2007). Firm platelet-platelet cohesion and aggregation requires activation of integrin $\alpha \mathrm{IIb} \beta 3$, which is present at $60-80,000$ copies per platelet (Hynes 2002; Bennett et al. 2009; Li et al. 2010). On resting platelets, $\alpha \operatorname{IIb} \beta 3$ is in an inactive state and does not bind any ligands. However, activation of platelets by signaling from GPIb-V-IX or GPVI/Fc $\gamma$ R (see Fig. 3) or by soluble agonists such as thrombin, the product of the clotting cascade, or ADP and thromboxane A2, so-called second-wave mediators released by already activated platelets, causes "inside-out" activation of $\alpha \mathrm{IIb} \beta 3$. Its subsequent interaction with ECM ligands deposited on the surface of the growing thrombus leads to platelet aggregation and formation of an occlusive thrombus. The major ligand for $\alpha \operatorname{IIb} \beta 3$ is fibrinogen, present in plasma at $2-$ $4 \mathrm{mg} / \mathrm{ml}(\sim 10 \mu \mathrm{M})$. The major binding site for $\alpha I I b \beta 3$ is a KQGADV sequence near the carboxyl terminus of the $\gamma$ chain of fibrinogen. Other known ligands for $\alpha I I b \beta 3$ include VWF, fibronectin, thrombospondin, and vitronectin, all of which contain RGD sequences critical for binding to $\alpha \mathrm{IIb} \beta 3$ integrin. Studies using mouse models of thrombosis have implicated all of these ECM proteins to one degree or another in formation of stable platelet aggregates in vivo (Denis and Wagner 2007; Maurer et al. 2010)

The platelet thrombus is further stabilized by the engagement of additional receptor-ligand pairs, such as Gas-6 and its receptors (Tyro3, Axl, and Mer), ephrin and Eph receptor kinases, or CD40 ligand and $\alpha \mathrm{IIb} \beta 3$ integrin (Brass et al. 2006). Many of these interactions, like those initiating platelet activation (discussed above) lead to activation of $\alpha \mathrm{IIb} \beta 3$ integrin by inside-out signaling (cf. Fig. 3). Once activated and engaged by ligand, $\alpha \operatorname{IIb} \beta 3$, like other integrins, also mediates outside-in signaling that further enhances platelet adhesion and aggregation (Shattil and Newman 2004). Finally, clot stability is greatly increased by the fibrin network, 
the result of the intrinsic and/or extrinsic activation of the coagulation cascade to cleave fibrinogen to fibrin (see below).

\section{RELATIVE CONTRIBUTION OF INDIVIDUAL PLATELET RECEPTORS AND ECM COMPONENTS TO THROMBOSIS AND HEMOSTASIS}

The critical contributions of GPIb-V-IX and $\alpha \mathrm{IIb} \beta 3$ integrin to arterial thrombosis are well documented (Nurden 1999; Ruggeri 2002). Patients with defective expression of either receptor suffer from a markedly increased risk of bleeding. These hemostatic defects can be recapitulated in mice by genetic deletion of the respective receptors (Hodivala-Dilke et al. 1999; Ware et al. 2000). These mice are also strongly protected in various models of thrombotic disease, including localized thrombosis in the micro- and macrocirculation and ischemic stroke (Stegner and Nieswandt 2011). In contrast, patients with a deficiency in GPVI show only a mild bleeding phenotype (Moroi et al. 1989; Arai et al. 1995; Dumont et al. 2009; Hermans et al. 2009). Consistent with this finding, mice lacking GPVI are characterized by an almost normal hemostatic response (Kato et al. 2003). When tested in experimental models of thrombotic disease, these mice show various degrees of protection, a finding that is likely a reflection of the collagen dependencies of the thrombosis models (Dubois et al. 2006; Hechler et al. 2010). Mice deficient in $\alpha 2$ integrins or lacking all $\beta 1$ integrins on platelets showed little protection from experimental thrombosis and are not susceptible to bleeding (Nuyttens et al. 2011). Importantly, however, infusion of a GPVI-blocking antibody markedly increased the bleeding risk in $\alpha 2$-deficient mice, suggesting that the importance of $\alpha 2 \beta 1$ is masked by GPVI, and that these two receptors have partially redundant functions (Gruner et al. 2004).

Redundancy was also observed in studies on the prothrombotic role of individual matrix components. Mice deficient in VWF are characterized by reduced platelet adhesion to the ECM, a delayed onset of thrombus formation, and the formation of almost occlusive thrombi that nonetheless retain open channels, presumably because of the requirement for VWF for effective platelet recruitment at high shear stress (Denis et al. 1998; Ni et al. 2000). This phenotype is less severe than that observed in mice with impaired GPIb $\alpha$ expression (Bergmeier et al. 2006), suggesting that other GPIb $\alpha$ ligands such as thrombospondin-1 may partially compensate for VWF. In contrast, thrombi form rapidly in mice lacking fibrinogen, but these thrombi are not firmly anchored to the vessel wall and thus frequently embolize ( $\mathrm{Ni}$ et al. 2000; Jirouskova et al. 2004). Deficiency in plasma fibronectin, on the contrary, delays formation of occlusive thrombosis because the developing thrombi continually shed platelets, possibly owing to a role for fibronectin in stabilizing platelet-platelet interactions in the growing thrombus (Ni et al. 2003; Cho and Mosher, 2006; Matuskova et al. 2006;). An alternative possibility is that the absence of fibronectin, which normally becomes cross-linked to fibrin in the forming clot through the action of factor XIII transglutaminase, leads to reduced plateletfibrin interactions or to a friable fibrin clot. Interestingly, mice lacking both VWF and fibrinogen (Ni et al. 2000) or all three of VWF, fibrinogen, and plasma fibronectin (Reheman et al. 2009), are still able to form thrombi, albeit less well. Thus, there is substantial redundancy among individual matrix components in their ability to promote thrombosis and hemostasis.

It seems likely that the relative contributions of the different ECM ligands may well differ depending on the degree of injury and the type of vessel involved. As noted earlier and in Figure 1, the diversity of ECM ligands available varies greatly among vessels and is further altered in disease states. As one example, fibronectin levels and inclusion of the alternatively spliced segments, EIIIA and EIIIB, increase in atherosclerotic plaques, in vessel walls after myocardial infarction, and in cancer (Astrof and Hynes, 2009), and mice engineered to express EIIIA ${ }^{+}$ fibronectin in their plasma, in which it is normally absent, show enhanced thrombosis (Chauhan et al. 2008). It is therefore plausible that the ability of platelets to recognize diverse ECM ligands may lead to differences in the 
W. Bergmeier and R.O. Hynes

strength of the thrombotic response in disease states. This issue needs further investigation.

\section{CELLULAR INTERACTIONS WITH THE FIBRIN CLOT: RETRACTION AND WOUND HEALING}

Once the fibrin clot has formed, with activated platelets incorporated into and onto it and frequently with other cells (erythrocytes, leukocytes) associated with it, the clot serves as the substrate for subsequent wound healing. Fibrin is essentially a neomatrix or facultative matrix induced by the processes of thrombosis and coagulation. Platelets embedded in the clot are attached to the fibrin via activated integrin $\alpha \operatorname{IIb} \beta 3$ that is, in turn, linked to the cytoskeleton. Like other integrin-cytoskeleton connections, the $\alpha I I b \beta 3$-fibrin linkage can exert force leading to clot retraction. Based on studies with Glanzmann thrombasthenia patients (Nurden 2006) and with mice lacking $\alpha \operatorname{IIb} \beta 3$ (Hodivala-Dilke et al. 1999), clot retraction is fully dependent on this integrin. Contraction of the clot closes the lesion in the blood vessel that has been occluded by the clot and can also contribute to broader wound closure.

However, much of that subsequent closure relies on other cells recruited to the damaged area, as does subsequent resorption of the clot. Those recruited cells rely on the so-called provisional fibrin matrix for their ability to migrate into the wound region. Key among the cells involved in wound repair are fibroblastic cells and leukocytes. The fibrin clot includes other ECM proteins, most notably fibronectin crosslinked by factor XIII, which is crucial for fibroblast migration into the clot (Hynes, 1990). The fibroblasts become transformed into contractile myofibroblasts, at least in part under the influence of TGF- $\beta$, which is rich in clots, probably mostly provided by the platelets, which are major sources of this factor (Assoian and Sporn 1986). TGF- $\beta$ up-regulates synthesis of many ECM proteins, including interstitial collagen and fibronectin, and induces inclusion of the alternatively spliced fibronectin domains EIIIA and EIIIB (Leask and Abraham 2004). It is perhaps of some interest that, although plasma fibronectin lacks these two spliced segments, platelet fibronectin, which is released from $\alpha$ granules on platelet activation does include them (Hynes 1990). The exact functions of these splice segments in wound healing remain unclear but they are necessary for proper vascular development and may play a role in angiogenesis (Astrof et al. 2007; Astrof and Hynes 2009). It is clear that the new ECM formed during the hemostatic response and deposited in the wound bed is an important part of the overall process of wound closure. Although the platelets contribute the initial clot retraction, the subsequent retraction of the wound ECM is accomplished by the fibroblasts recruited to the provisional fibrin-rich matrix laid down during thrombosis. However, the TGF- $\beta$ contributed by the platelets and the provisional ECM of the clot play key roles in generating the granulation tissue (ECM and fibroblasts).

The seeds of clot dissolution are also incorporated during the initial thrombotic process. Tissue plasminogen activator (tPA) has a relatively high affinity for fibrin, to which it binds through an FN1 domain homologous with the fibrin-binding domains of fibronectin. Because of this, tPA becomes incorporated into the clot (Medved and Nieuwenhuizen 2003). Subsequent activation of plasminogen to active plasmin by the tPA is key to the dissolution of the clot. The high affinity of tPA for fibrin clots forms the basis for its use as a "clot buster," therapeutic in cases of myocardial infarction and stroke.

Incorporation or recruitment of leukocytes into the clot and the subsequent provisional and wound healing matrices requires their affinity for those matrices. The integrin $\alpha \mathrm{M} \beta 2$ (also known as Mac-1, CR3, or CD11bCD18) and its sister, $\alpha \mathrm{X} \beta 2$, both recognize and bind fibrin (Wright et al. 1988; Loike et al. 1991). $\alpha \mathrm{M} \beta 2$ also acts as a chemotactic receptor to fibrin degradation products. Migration of leukocytes into the provisional and wound matrices provides a source of cells, specialized to degrade and remove these matrices because these cells produce multiple proteolytic enzymes and are actively phagocytic. 


\section{CONCLUDING REMARKS}

The detailed understanding of the adhesion and aggregation mechanisms of platelets has already provided many effective antithrombotic drugs targeting either the activation pathways necessary for inside-out activation of $\alpha \operatorname{IIb} \beta 3$ for binding of its ECM ligands or the multiple receptor-ECM interactions mediating platelet adhesion and aggregation, and further studies underway show promise for additional therapeutic interventions.

Antiplatelet drugs already in clinical use target (1) the generation of the second-wave mediator thromboxane A2 (aspirin), (2) positive feedback activation by the second-wave mediator ADP (clopidogrel, prasugrel), and (3) the major platelet integrin, $\alpha \mathrm{IIb} \beta 3$ (ReoPro, Integrilin, Aggrastat).

Aspirin and clopidogrel/prasugel are orally deliverable and suitable for routine preventive dosing against thrombotic events. The drugs targeting $\alpha \mathrm{IIb} \beta 3$ are all injectables and are commonly used to prevent reocclusion after angioplasty. Drugs directed against several other platelet proteins are in (pre)clinical evaluation (De Meyer et al. 2008; Siller-Matula et al. 2010). These include inhibitors of the thrombin receptor PAR1, the GPCR receptors for thromboxane, and the ECM receptors GPVI and GPIb $\alpha$. In fact, several strategies to disrupt the VWF-GPIb $\alpha$ interaction are currently under investigation: (1) direct inhibitors of GPIb $\alpha$, (2) inhibitors targeting the A1 domain of VWF, (3) molecules that disrupt the interaction of collagen with the A3 domain in VWF, and (4) recombinant ADAMTS-13 as an attempt to lower the adhesiveness of VWF. The success of these novel interventions will depend on their ability to reduce the risk of thrombotic complications without markedly increasing the risk of bleeding in the patient.

The identification of new targets for safe interventions against atherothrombosis strongly depends on studies in animal (mouse) models of thrombosis. One of the various limitations of this approach, however, arises from the fact that thrombosis has typically been studied in otherwise healthy vessels, i.e., on an exposed
ECM that is likely much different from that found on a ruptured atherosclerotic plaque, which is known to contain altered ECM (e.g., collagens, fibrin, fibronectins). To address this shortcoming and to develop better models of atherothrombotic events, several laboratories have now started to evaluate thrombosis in apoE-deficient mice, which develop atherosclerotic plaques and in which plaque rupture can be induced mechanically or by ultrasound treatment (Kuijpers et al. 2009; Hechler and Gachet 2011). Alternatively, adhesion of human platelets is studied in human blood perfused over homogenized plaque material (Cosemans et al. 2005; Penz et al. 2005; Schulz et al. 2008; Reininger et al. 2010). The results from these studies confirm the predicted concomitant involvement of collagen-induced platelet activation and tissue factor-triggered thrombin generation and fibrin formation. As in other thrombosis models, the collagen-GPVI interaction seems to be prominent after mild injury to the plaque (induced by ultrasound), whereas plaque rupture causes a more thrombindependent response. Thus, studying thrombosis on the ruptured/homogenized plaque material may become a new gold standard for the validation of novel antithrombotic targets.

\section{ACKNOWLEDGMENTS}

We gratefully acknowledge support by grants from the American Heart Association (W.B.), the American Society of Hematology (W.B.), the National Heart, Lung, and Blood Institute (W.B. and R.O.H.), the National Cancer Institute (R.O.H.), and the Howard Hughes Medical Institute (R.O.H.).

\section{REFERENCES}

Andrews RK, Gardiner EE, Shen Y, Whisstock JC, Berndt MC. 2003. Glycoprotein Ib-IX-V. Int J Biochem Cell Biol 35: $1170-1174$.

Andrews RK, Du X, Berndt MC. 2007. The 14-3-3 $\zeta$-GPIb-IX-V complex as an antiplatelet target. Drug News Perspect 20: 285-292.

Arai M, Yamamoto N, Moroi M, Akamatsu N, Fukutake K, Tanoue K. 1995. Platelets with $10 \%$ of the normal amount of glycoprotein VI have an impaired response 
W. Bergmeier and R.O. Hynes

to collagen that results in a mild bleeding tendency. $\mathrm{Br} J$ Haematol 89: 124-130.

Arya M, Lopez JA, Romo GM, Dong JF, McIntire LV, Moake JL, Anvari B. 2002. Measurement of the binding forces between von Willebrand factor and variants of platelet glycoprotein Ib $\alpha$ using optical tweezers. Lasers Surg Med 30: 306-312.

Assoian RK, Sporn MB. 1986. Type $\beta$ transforming growth factor in human platelets: Release during platelet degranulation and action on vascular smooth muscle cells. J Cell Biol 102: 1217-1223.

Astrof S, Hynes RO. 2009. Fibronectins in vascular morphogenesis. Angiogenesis 12: 165-175.

Astrof S, Crowley D, Hynes RO. 2007. Multiple cardiovascular defects caused by the absence of alternatively spliced segments of fibronectin. Dev Biol 311: 11-24.

Banno F, Kokame K, Okuda T, Honda S, Miyata S, Kato H, Tomiyama Y, Miyata T. 2006. Complete deficiency in ADAMTS13 is prothrombotic, but it alone is not sufficient to cause thrombotic thrombocytopenic purpura. Blood 107: 3161-3166.

Bennett JS, Berger BW, Billings PC. 2009. The structure and function of platelet integrins. J Thromb Haemost 7 (Suppl 1): 200-205.

Bergmeier W, Piffath CL, Goerge T, Cifuni SM, Ruggeri ZM, Ware J, Wagner DD. 2006. The role of platelet adhesion receptor GPIb $\alpha$ far exceeds that of its main ligand, von Willebrand factor, in arterial thrombosis. Proc Nat Acad Sci 103: 16900-16905.

Bergmeier W, Chauhan AK, Wagner DD. 2008. Glycoprotein $\mathrm{Ib} \alpha$ and von Willebrand factor in primary platelet adhesion and thrombus formation: Lessons from mutant mice. Thromb Haemost 99: 264-270.

Bernard J, Soulier JP. 1948. Sur une nouvelle variete de dystrophie thrombocytaire-hemorragipare congenitale. Semin Hop Paris 24: 3217-3223.

Brass LF, Jiang H, Wu J, Stalker TJ, Zhu L. 2006. Contactdependent signaling events that promote thrombus formation. Blood Cells Mol Dis 36: 157-161.

Caen JP, Nurden AT, Jeanneau C, Michel H, Tobelem G, Levy-Toledano S, Sultan Y, Valensi F, Bernard J. 1976 Bernard-Soulier syndrome: A new platelet glycoprotein abnormality. Its relationship with platelet adhesion to subendothelium and with the factor VIII von Willebrand protein. J Lab Clin Med 87: 586-596.

Campbell ID, Humphries MJ. 2011. Integrin structure, activation, and interactions. Cold Spring Harb Perspect Biol doi: $10.1101 /$ cshperspect.a004994.

Chauhan AK, Kisucka J, Lamb CB, Bergmeier W, Wagner DD. 2007. von Willebrand factor and factor VIII are independently required to form stable occlusive thrombi in injured veins. Blood 109: 2424-2429.

Chauhan AK, Kisucka J, Cozzi MR, Walsh MT, Moretti FA, Battiston M, Mazzucato M, De Marco L, Baralle FE, Wagner DD, et al. 2008. Prothrombotic effects of fibronectin isoforms containing the EDA domain. Arterioscler Thromb Vasc Biol 28: 296-301.

Chen Z, Lou J, Zhu C, Schulten K. 2008. Flow-induced structural transition in the $\beta$-switch region of glycoprotein Ib. Biophys J 95: 1303-1313.
Cho J, Mosher DF. 2006. Enhancement of thrombogenesis by plasma fibronectin cross-linked to fibrin and assembled in platelet thrombi. Blood 107: 3555-3563.

Clemetson KJ, Clemetson JM. 2001. Platelet collagen receptors. Thromb Haemost 86: 189-197.

Clemetson KJ, Clemetson JM. 2008. Platelet GPIb complex as a target for anti-thrombotic drug development. Thromb Haemost 99: 473-479.

Cosemans JM, Kuijpers MJ, Lecut C, Loubele ST, Heeneman S, Jandrot-Perrus M, Heemskerk JW. 2005. Contribution of platelet glycoprotein VI to the thrombogenic effect of collagens in fibrous atherosclerotic lesions. Atherosclerosis 181: 19-27.

Crittenden JR, Bergmeier W, Zhang Y, Piffath CL, Liang Y, Wagner DD, Housman DE, Graybiel AM. 2004. CalDAGGEFI integrates signaling for platelet aggregation and thrombus formation. Nat Med 10: 982-986.

Dale GL. 2005. Coated-platelets: An emerging component of the procoagulant response. J Thromb Haemost 3: 2185-2192.

Deckmyn H, Cauwenberghs N, Wu D, Depraetere H, Vanhoorelbeke K. 2005. Development of antibodies that interfere with the collagen-VWF-GPIb axis as new antithrombotics. Verh K Acad Geneeskd Belg 67: 55-65.

De Meyer SF, Vanhoorelbeke K, Broos K, Salles II, Deckmyn H. 2008. Antiplatelet drugs. Br J Haematol 142: 515-528.

Denis CV, Wagner DD. 2007. Platelet adhesion receptors and their ligands in mouse models of thrombosis. Arterioscler Thromb Vasc Biol 27: 728-739.

Denis C, Methia N, Frenette PS, Rayburn H, Ullman-Cullere M, Hynes RO, Wagner DD. 1998. A mouse model of severe von Willebrand disease: Defects in hemostasis and thrombosis. Proc Natl Acad Sci 95: 9524-9529.

Doggett TA, Girdhar G, Lawshe A, Miller JL, Laurenzi IJ, Diamond SL, Diacovo TG. 2003. Alterations in the intrinsic properties of the GPIb $\alpha$-VWF tether bond define the kinetics of the platelet-type von Willebrand disease mutation, Gly233Val. Blood 102: 152-160.

$\mathrm{Du}$ X. 2007. Signaling and regulation of the platelet glycoprotein Ib-IX-V complex. Curr Opin Hematol 14: $262-$ 269.

Dubois C, Panicot-Dubois L, Merrill-Skoloff G, Furie B, Furie BC. 2006. Glycoprotein VI-dependent and -independent pathways of thrombus formation in vivo. Blood 107: 3902-3906.

Dumas JJ, Kumar R, McDonagh T, Sullivan F, Stahl ML, Somers WS, Mosyak L. 2004. Crystal structure of the wild-type von Willebrand factor A1-glycoprotein Ib $\alpha$ complex reveals conformation differences with a complex bearing von Willebrand disease mutations. J Biol Chem 279: $23327-23334$.

Dumont B, Lasne D, Rothschild C, Bouabdelli M, Ollivier V, Oudin C, Ajzenberg N, Grandchamp B, Jandrot-Perrus M. 2009. Absence of collagen-induced platelet activation caused by compound heterozygous GPVI mutations. Blood 114: 1900-1903.

Emsley J, Knight CG, Farndale RW, Barnes MJ, Liddington RC. 2000. Structural basis of collagen recognition by integrin $\alpha 2 \beta 1$. Cell 101: 47-56.

Furlan M, Lammle B. 2001. Aetiology and pathogenesis of thrombotic thrombocytopenic purpura and haemolytic 
uraemic syndrome: The role of von Willebrand factorcleaving protease. Best Pract Res Clin Haematol 14: 437-454.

Gruner S, Prostredna M, Aktas B, Moers A, Schulte V, Krieg T, Offermanns S, Eckes B, Nieswandt B. 2004 Anti-glycoprotein VI treatment severely compromises hemostasis in mice with reduced $\alpha 2 \beta 1$ levels or concomitant aspirin therapy. Circulation 110: 2946-2951.

Hallmann R, Horn N, Selg M, Wendler O, Pausch F, Sorokin LM. 2005. Expression and function of laminins in the embryonic and mature vasculature. Physiol Rev 85: 979-1000.

Harper MT, Poole AW. 2010. Diverse functions of protein kinase $\mathrm{C}$ isoforms in platelet activation and thrombus formation. J Thromb Haemost 8: 454-462.

Hechler B, Gachet C. 2011. Comparison of two murine models of thrombosis induced by atherosclerotic plaque injury. Thromb Haemost 105 (Suppl 1): S3-12.

Hechler B, Nonne C, Eckly A, Magnenat S, Rinckel JY, Denis CV, Freund M, Cazenave JP, Lanza F, Gachet C. 2010. Arterial thrombosis: Relevance of a model with two levels of severity assessed by histologic, ultrastructural and functional characterization. J Thromb Haemost 8: 173-184.

Heemskerk JW, Siljander P, Vuist WM, Breikers G, Reutelingsperger CP, Barnes MJ, Knight CG, Lassila R, Farndale RW. 1999. Function of glycoprotein VI and integrin $\alpha 2 \beta 1$ in the procoagulant response of single, collagen-adherent platelets. Thromb Haemost 81: 782 792.

Henrita van Zanten G, Saelman EU, Schut-Hese KM, Wu YP, Slootweg PJ, Nieuwenhuis HK, de Groot PG, Sixma JJ. 1996. Platelet adhesion to collagen type IV under flow conditions. Blood 88: 3862-3871.

Hermans C, Wittevrongel C, Thys C, Smethurst PA, Van Geet C, Freson K. 2009. A compound heterozygous mutation in glycoprotein VI in a patient with a bleeding disorder. J Thromb Haemost 7: 1356-1363.

Hodivala-Dilke KM, McHugh KP, Tsakiris DA, Rayburn H, Crowley D, Ullman-Cullere M, Ross FP, Coller BS, Teitelbaum S, Hynes RO. 1999. $\beta 3$-integrin-deficient mice are a model for Glanzmann thrombasthenia showing placental defects and reduced survival. J Clin Invest 103: 229-238.

Horii K, Kahn ML, Herr AB. 2006. Structural basis for platelet collagen responses by the immune-type receptor glycoprotein VI. Blood 108: 936-942.

Huizinga EG, Tsuji S, Romijn RA, Schiphorst ME, de Groot PG, Sixma JJ, Gros P. 2002. Structures of glycoprotein Iba and its complex with von Willebrand factor A1 domain. Science 297: 1176-1179.

Hynes RO. 1990. Fibronectins. Springer-Verlag, New York.

Hynes RO. 2002. Integrins: Bidirectional, allosteric signaling machines. Cell 110: 673-687.

Ill CR, Engvall E, Ruoslahti E. 1984. Adhesion of platelets to laminin in the absence of activation. J Cell Biol 99: $2140-2145$.

Inoue O, Suzuki-Inoue K, McCarty OJ, Moroi M, Ruggeri ZM, Kunicki TJ, Ozaki Y, Watson SP. 2006. Laminin stimulates spreading of platelets through integrin $\alpha 6 \beta 1$-dependent activation of GPVI. Blood 107: 14051412.
Jarvis GE, Atkinson BT, Snell DC, Watson SP. 2002. Distinct roles of GPVI and integrin $\alpha(2) \beta(1)$ in platelet shape change and aggregation induced by different collagens. Br J Pharmacol 137: 107-117.

Jirouskova M, Chereshnev I, Vaananen H, Degen JL, Coller BS. 2004. Antibody blockade or mutation of the fibrinogen $\gamma$-chain C-terminus is more effective in inhibiting murine arterial thrombus formation than complete absence of fibrinogen. Blood 103: 1995-2002.

Jung SM, Moroi M. 2008. Platelet glycoprotein VI. Adv Exp Med Biol 640: 53-63.

Jung SM, Takemura Y, Imamura Y, Hayashi T, Adachi E, Moroi M. 2008. Collagen-type specificity of glycoprotein VI as a determinant of platelet adhesion. Platelets 19: $32-42$.

Kato K, Kanaji T, Russell S, Kunicki TJ, Furihata K, Kanaji S, Marchese P, Reininger A, Ruggeri ZM, Ware J. 2003. The contribution of glycoprotein VI to stable platelet adhesion and thrombus formation illustrated by targeted gene deletion. Blood 102: 1701-1707.

Kehrel B, Balleisen L, Kokott R, Mesters R, Stenzinger W, Clemetson KJ, van de Loo J. 1988. Deficiency of intact thrombospondin and membrane glycoprotein Ia in platelets with defective collagen-induced aggregation and spontaneous loss of disorder. Blood 71: 1074-1078.

Kim J, Zhang CZ, Zhang X, Springer TA. 2010. A mechanically stabilized receptor-ligand flex-bond important in the vasculature. Nature 466: 992-995.

Knight CG, Morton LF, Onley DJ, Peachey AR, Ichinohe T, Okuma M, Farndale RW, Barnes MJ. 1999. Collagenplatelet interaction: Gly-Pro-Hyp is uniquely specific for platelet Gp VI and mediates platelet activation by collagen. Cardiovasc Res 41: 450-457.

Kuijpers MJ, Pozgajova M, Cosemans JM, Munnix IC, Eckes B, Nieswandt B, Heemskerk JW. 2007. Role of murine integrin $\alpha 2 \beta 1$ in thrombus stabilization and embolization: Contribution of thromboxane A2. Thromb Haemost 98: $1072-1080$.

Kuijpers MJ, Gilio K, Reitsma S, Nergiz-Unal R, Prinzen L, Heeneman S, Lutgens E, van Zandvoort MA, Nieswandt B, Egbrink MG, et al. 2009. Complementary roles of platelets and coagulation in thrombus formation on plaques acutely ruptured by targeted ultrasound treatment: A novel intravital model. J Thromb Haemost 7: 152-161.

Kulkarni S, Dopheide SM, Yap CL, Ravanat C, Freund M, Mangin P, Heel KA, Street A, Harper IS, Lanza F, et al. 2000. A revised model of platelet aggregation. JClin Invest 105: $783-791$.

Kunicki TJ, Kritzik M, Annis DS, Nugent DJ. 1997. Hereditary variation in platelet integrin $\alpha_{2} \beta_{1}$ density is associated with two silent polymorphisms in the $\alpha_{2}$ gene coding sequence. Blood 89: 1939-1943.

Lammle B, Kremer Hovinga JA, Alberio L. 2005. Thrombotic thrombocytopenic purpura. J Thromb Haemost 3: $1663-1675$.

Leask A, Abraham DJ. 2004. TGF- $\beta$ signaling and the fibrotic response. FASEB J 18:816-827.

Levy GG, Nichols WC, Lian EC, Foroud T, McClintick JN, McGee BM, Yang AY, Siemieniak DR, Stark KR, Gruppo $\mathrm{R}$, et al. 2001. Mutations in a member of the ADAMTS gene family cause thrombotic thrombocytopenic purpura. Nature 413: 488-494. 
W. Bergmeier and R.O. Hynes

Li Z, Delaney MK, O’Brien KA, Du X. 2010. Signaling during platelet adhesion and activation. Arterioscler Thromb Vasc Biol 30: 2341-2349.

Loike JD, Sodeik B, Cao L, Leucona S, Weitz JI, Detmers PA, Wright SD, Silverstein SC. 1991. CD11c/CD18 on neutrophils recognizes a domain at the $\mathrm{N}$ terminus of the A $\alpha$ chain of fibrinogen. Proc Natl Acad Sci 88: 1044-1048.

Lou J, Zhu C. 2008. Flow induces loop-to- $\beta$-hairpin transition on the $\beta$-switch of platelet glycoprotein Ib $\alpha$. Proc Natl Acad Sci 105: 13847-13852.

Luo SZ, Mo X, Afshar-Kharghan V, Srinivasan S, Lopez JA, Li R. 2007. Glycoprotein Ib $\alpha$ forms disulfide bonds with 2 glycoprotein Ib $\beta$ subunits in the resting platelet. Blood 109: 603-609.

Matuskova J, Chauhan AK, Cambien B, Astrof S, Dole VS, Piffath CL, Hynes RO, Wagner DD. 2006. Decreased plasma fibronectin leads to delayed thrombus growth in injured arterioles. Arterioscler Thromb Vasc Biol 26: 1391-1396.

Maurer LM, Tomasini-Johansson BR, Mosher DF. 2010. Emerging roles of fibronectin in thrombosis. Thromb Res 125: 287-291.

Medved L, Nieuwenhuizen W. 2003. Molecular mechanisms of initiation of fibrinolysis by fibrin. Thromb Haemost 89:409-419.

Moriki T, Murata M, Kitaguchi T, Anbo H, Handa M, Watanabe K, Takahashi H, Ikeda Y. 1997. Expression and functional characterization of an abnormal platelet membrane glycoprotein $\mathrm{Ib} \alpha\left(\mathrm{Met}^{239} \rightarrow \mathrm{Val}\right)$ reported in patients with platelet-type von Willebrand disease. Blood 90: 698-705.

Moroi M, Jung SM, Okuma M, Shinmyozu K. 1989. A patient with platelets deficient in glycoprotein VI that lack both collagen-induced aggregation and adhesion. J Clin Invest 84: 1440-1445.

Moser M, Nieswandt B, Ussar S, Pozgajova M, Fassler R. 2008. Kindlin-3 is essential for integrin activation and platelet aggregation. Nat Med 14: 325-330.

Motto DG, Chauhan AK, Zhu G, Homeister J, Lamb CB, Desch KC, Zhang W, Tsai HM, Wagner DD, Ginsburg D. 2005. Shigatoxin triggers thrombotic thrombocytopenic purpura in genetically susceptible ADAMTS13deficient mice. J Clin Invest 115: 2752-2761.

Nelson J, McFerran NV, Pivato G, Chambers E, Doherty C, Steele D, Timson DJ. 2008. The $67 \mathrm{kDa}$ laminin receptor: Structure, function and role in disease. Biosci Rep 28: 33-48.

Ni H, Denis CV, Subbarao S, Degen JL, Sato TN, Hynes RO, Wagner DD. 2000. Persistence of platelet thrombus formation in arterioles of mice lacking both von Willebrand factor and fibrinogen. J Clin Invest 106: 385-392.

Ni H, Yuen PS, Papalia JM, Trevithick JE, Sakai T, Fassler R, Hynes RO, Wagner DD. 2003. Plasma fibronectin promotes thrombus growth and stability in injured arterioles. Proc Natl Acad Sci 100: 2415-2419.

Nieswandt B, Watson SP. 2003. Platelet-collagen interaction: Is GPVI the central receptor? Blood 102: 449-461.

Nieswandt B, Brakebusch C, Bergmeier W, Schulte V, Bouvard D, Mokhtari-Nejad R, Lindhout T, Heemskerk JW, Zirngibl H, Fassler R. 2001. Glycoprotein VI but not $\alpha 2 \beta 1$ integrin is essential for platelet interaction with collagen. Embo J 20: 2120-2130.

Nieswandt B, Moser M, Pleines I, Varga-Szabo D, Monkley S, Critchley D, Fassler R. 2007. Loss of talin1 in platelets abrogates integrin activation, platelet aggregation, and thrombus formation in vitro and in vivo. J Exp Med 204: 3113-3118.

Nieuwenhuis HK, Akkerman JW, Houdijk WP, Sixma JJ. 1985. Human blood platelets showing no response to collagen fail to express surface glycoprotein Ia. Nature 318: $470-472$.

Nurden AT. 1999. Inherited abnormalities of platelets. Thromb Haemost 82: 468-480.

Nurden AT. 2006. Glanzmann thrombasthenia. Orphanet J Rare Dis 1: 10. doi: 10.1186/1750-1172-1-10.

Nuyttens BP, Thijs T, Deckmyn H, Broos K. 2011. Platelet adhesion to collagen. Thromb Res 127 (Suppl 2): S26S29.

Ozaki Y, Suzuki-Inoue K, Inoue O. 2009. Novel interactions in platelet biology: CLEC-2/podoplanin and laminin/ GPVI. J Thromb Haemost 7 (Suppl 1): 191-194.

Penz S, Reininger AJ, Brandl R, Goyal P, Rabie T, Bernlochner I, Rother E, Goetz C, Engelmann B, Smethurst PA, et al. 2005. Human atheromatous plaques stimulate thrombus formation by activating platelet glycoprotein VI. FASEB J 19: 898-909.

Petrich BG, Marchese P, Ruggeri ZM, Spiess S, Weichert RA, Ye F, Tiedt R, Skoda RC, Monkley SJ, Critchley DR, et al. 2007. Talin is required for integrin-mediated platelet function in hemostasis and thrombosis. J Exp Med 204: 3103-3111.

Reheman A, Yang H, Zhu G, Jin W, He F, Spring CM, Bai X, Gross PL, Freedman J, Ni H. 2009. Plasma fibronectin depletion enhances platelet aggregation and thrombus formation in mice lacking fibrinogen and von Willebrand factor. Blood 113: 1809-1817.

Reininger AJ, Bernlochner I, Penz SM, Ravanat C, Smethurst P, Farndale RW, Gachet C, Brandl R, Siess W. 2010. A 2-step mechanism of arterial thrombus formation induced by human atherosclerotic plaques. J Am Coll Cardiol 55: 1147-1158.

Ricard-Blum S. 2011. The collagen family. Cold Spring Harb Perspect Biol doi: 10.1101/cshperspect.a004978.

Ruggeri ZM. 1997. von Willebrand factor. J Clin Invest 100: S41-S46.

Ruggeri ZM. 2002. Platelets in atherothrombosis. Nat Med 8: $1227-1234$.

Russell SD, Roth GJ. 1993. Pseudo-von Willebrand disease: A mutation in the platelet glycoprotein Ib $\alpha$ gene associated with a hyperactive surface receptor. Blood 81: 1787-1791.

Sadler JE. 2008. Von Willebrand factor, ADAMTS13, and thrombotic thrombocytopenic purpura. Blood 112: $11-18$.

Sadler JE. 2009. von Willebrand factor assembly and secretion. J Thromb Haemost 7 (Suppl 1): 24-27.

Savage B, Saldivar E, Ruggeri ZM. 1996. Initiation of platelet adhesion by arrest onto fibrinogen or translocation on von Willebrand factor. Cell 84: 289-297.

Schneider SW, Nuschele S, Wixforth A, Gorzelanny C, Alexander-Katz A, Netz RR, Schneider MF. 2007. 
Extracellular Matrix Proteins in Hemostasis and Thrombosis

Shear-induced unfolding triggers adhesion of von Willebrand factor fibers. Proc Natl Acad Sci 104: 7899-7903.

Schulz C, Penz S, Hoffmann C, Langer H, Gillitzer A, Schneider S, Brandl R, Seidl S, Massberg S, Pichler B, et al. 2008. Platelet GPVI binds to collagenous structures in the core region of human atheromatous plaque and is critical for atheroprogression in vivo. Basic Res Cardiol 103: $356-367$.

Schwarzbauer J, DeSimone D. 2011. Fibronectins, their fibrillogenesis, and in vivo functions. Cold Spring Harb Perspect Biol 3: doi: 10.1101/cshperspect.a005041.

Shattil SJ, Newman PJ. 2004. Integrins: Dynamic scaffolds for adhesion and signaling in platelets. Blood 104: $1606-1615$.

Siller-Matula JM, Krumphuber J, Jilma B. 2010. Pharmacokinetic, pharmacodynamic and clinical profile of novel antiplatelet drugs targeting vascular diseases. $\mathrm{Br} \mathrm{J}$ Pharmacol 159: 502-517.

Sixt M, Engelhardt B, Pausch F, Hallmann R, Wendler O, Sorokin LM. 2001. Endothelial cell laminin isoforms, laminins 8 and 10, play decisive roles in T cell recruitment across the blood-brain barrier in experimental autoimmune encephalomyelitis. J Cell Biol 153: 933-946.

Sonnenberg A, Modderman PW, Hogervorst F. 1988. Laminin receptor on platelets is the integrin VLA-6. Nature 336: $487-489$.

Stefanini L, Roden RC, Bergmeier W. 2009. CalDAG-GEFI is at the nexus of calcium-dependent platelet activation. Blood 114: 2506-2514.

Stegner D, Nieswandt B. 2011. Platelet receptor signaling in thrombus formation. J Mol Med (Berl) 89: 109-121.

Tandon NN, Holland EA, Kralisz U, Kleinman HK, Robey FA, Jamieson GA. 1991. Interaction of human platelets with laminin and identification of the $67 \mathrm{kDa}$ laminin receptor on platelets. Biochem J 274 (Pt 2): 535-542.

Varga-Szabo D, Pleines I, Nieswandt B. 2008. Cell adhesion mechanisms in platelets. Arterioscler Thromb Vasc Biol 28: $403-412$.
Veyradier A, Lavergne JM, Ribba AS, Obert B, Loirat C, Meyer D, Girma JP. 2004. Ten candidate ADAMTS13 mutations in six French families with congenital thrombotic thrombocytopenic purpura (Upshaw-Schulman syndrome). J Thromb Haemost 2: 424-429.

Voss B, Rauterberg J. 1986. Localization of collagen types I, III, IV and V, fibronectin and laminin in human arteries by the indirect immunofluorescence method. Pathol Res Pract 181: 568-575.

Wagenseil JE, Mecham RP. 2009. Vascular extracellular matrix and arterial mechanics. Physiol Rev 89: 957-989.

Wagner DD. 1990. Cell biology of von Willebrand factor. Annu Rev Cell Biol 6: 217-246.

Ware J, Russell S, Ruggeri ZM. 2000. Generation and rescue of a murine model of platelet dysfunction: The BernardSoulier syndrome. Proc Natl Acad Sci 97: 2803-2808.

Weiss HJ, Sussman II, Hoyer LW. 1977. Stabilization of factor VIII in plasma by the von Willebrand factor. Studies on posttransfusion and dissociated factor VIII and in patients with von Willebrand's disease. J Clin Invest 60: 390-404.

Wickström SA, Radovanac K, Fässler R. 2011. Genetic analyses of integrin signaling. Cold Spring Harb Perspect Biol doi: 10.1101/cshperspect.a005116.

Wright SD, Weitz JI, Huang AJ, Levin SM, Silverstein SC, Loike JD. 1988. Complement receptor type three (CD11b/CD18) of human polymorphonuclear leukocytes recognizes fibrinogen. Proc Natl Acad Sci 85: 7734-7738.

Yurchenco P. 2011. Basement membranes: Cell scaffoldings and signaling platforms. Cold Spring Harb Perspect Biol doi: $10.1101 /$ cshperspect.a004911.

Zhang X, Halvorsen K, Zhang CZ, Wong WP, Springer TA. 2009. Mechanoenzymatic cleavage of the ultralarge vascular protein von Willebrand factor. Science 324: $1330-1334$.

Zhou Z, Nguyen TC, Guchhait P, Dong JF. 2010. Von Willebrand factor, ADAMTS-13, and thrombotic thrombocytopenic purpura. Semin Thromb Hemost 36: 71-81. 


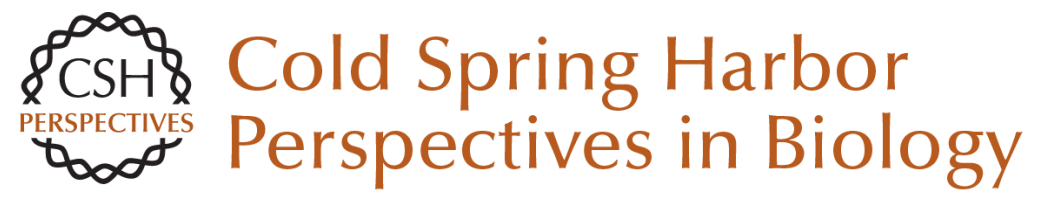

\title{
Extracellular Matrix Proteins in Hemostasis and Thrombosis
}

\author{
Wolfgang Bergmeier and Richard O. Hynes
}

Cold Spring Harb Perspect Biol 2012; doi: 10.1101/cshperspect.a005132 originally published online September 21, 2011

\section{Subject Collection Extracellular Matrix Biology}

Extracellular Matrix in Development: Insights from Mechanisms Conserved between Invertebrates and Vertebrates Nicholas H. Brown

Extracellular Matrix Proteins in Hemostasis and Thrombosis Wolfgang Bergmeier and Richard O. Hynes

The Thrombospondins Josephine C. Adams and Jack Lawler

Cross Talk among TGF- $\beta$ Signaling Pathways, Integrins, and the Extracellular Matrix John S. Munger and Dean Sheppard

Heparan Sulfate Proteoglycans Stephane Sarrazin, William C. Lamanna and Jeffrey D. Esko

The Collagen Family Sylvie Ricard-Blum

Tenascins and the Importance of Adhesion Modulation

Ruth Chiquet-Ehrismann and Richard P. Tucker Integrin Structure, Activation, and Interactions lain D. Campbell and Martin J. Humphries
Extracellular Matrix Degradation and Remodeling in Development and Disease

Pengfei Lu, Ken Takai, Valerie M. Weaver, et al.

Overview of the Matrisome--An Inventory of Extracellular Matrix Constituents and Functions Richard O. Hynes and Alexandra Naba

Integrins in Cell Migration Anna Huttenlocher and Alan Rick Horwitz

Fibronectins, Their Fibrillogenesis, and In Vivo Functions Jean E. Schwarzbauer and Douglas W. DeSimone

Extracellular Matrix: Functions in the Nervous System

Claudia S. Barros, Santos J. Franco and Ulrich Müller

Molecular Architecture and Function of Matrix Adhesions

Benjamin Geiger and Kenneth M. Yamada

Cell-Extracellular Matrix Interactions in Normal and Diseased Skin

Fiona M. Watt and Hironobu Fujiwara

Genetic Analyses of Integrin Signaling

Sara A. Wickström, Korana Radovanac and Reinhard Fässler

For additional articles in this collection, see http://cshperspectives.cshlp.org/cgi/collection/

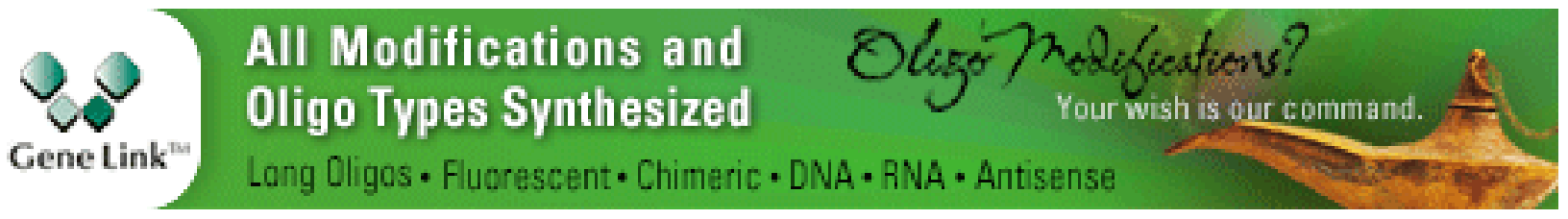

